\title{
LA RECEPCIÓN DE LA OBRA DE JEAN-BAPTISTE SAY EN ESPAÑA: LA TEORÍA ECONÓMICA DEL EMPRESARIO*
}

\author{
JOSÉ MANUEL MENUDO \\ Universidad Pablo de Olavide \\ JOSÉ MARÍA O’KEAN \\ Universidad Pablo de Olavide ${ }^{\mathrm{a}}$
}

\begin{abstract}
RESUMEN
Este trabajo analiza la difusión de la teoría del empresario de Jean-Baptiste Say en España, como último eslabón de una línea de pensamiento que tiene su origen en Richard Cantillon. Se prueba que la particularidad de este autor es su gran difusión en el siglo XIX español -siendo uno de los más traducidos- y la escasa influencia de su teoría económica del empresario. Explicamos las razones de una paradoja que deja sin fundamentos teóricos a cualquier política económica destinada al desarrollo del tejido empresarial nacional. Son presentados los mecanismos de difusión, tanto directos, por medio de traducciones, como indirectos, por medio de autores españoles que pudieron difundir esta teoría de la función empresarial. Nos interesa conocer la recepción por parte de los autores españoles de la teoría del empresario de Say, determinar su grado de comprensión, de interpretación en relación con la realidad nacional, de revisión teórica, e incluso conocer si la fuente real de la idea a transmitir es el propio autor o alguna otra.
\end{abstract}

* Damos las gracias por los constructivos comentarios recibidos en los diferentes escenarios en los que este trabajo de investigación ha sido expuesto en sus diferentes versiones, con especial referencia a Salvador Almenar, Antonio Miguel Bernal, Vicent Llombart, Manuel Santos, James Simpson y Carlos Usabiaga. Los comentarios de los tres evaluadores anónimos de esta Revista han contribuido a mejorar el trabajo, aunque cualquier error cometido es responsabilidad nuestra.

a Carretera de Utrera, Km. 1. E-41013, Sevilla.jmmenpac@upo.es; jmokean@upo.es 
Palabras clave: J. B. Say, historia del pensamiento económico, función empresarial

\begin{abstract}
This paper illustrates the spread of Jean-Baptiste Say's entrepreneur theory in Spain -a last contribution within the French tradition in which Richard Cantillon and A. R. J. Turgot were predecessors. We attempt to demonstrate that this is a special case, because, even though J. B. Say was the most important author from a publishing point of view, his economic theory of entrepreneurship had very little influence. The spread of economic ideas by way of translation and Spanish authors which employed J. B. Say's economic theory, give possible explanations to a paradox which had left economic policy without a theoretical reference. We analyse how Say's entrepreneur theory was received among Spanish authors in the $19^{\text {th }}$ century, its degree of comprehension and the analytical additions made, and attempt to identify the real source of transmission.
\end{abstract}

Keywords: J. B. Say, history of economic thought: classical, entrepreneurship JEL classification: A110, B120, M13

«En el año nono concurrirán ya estos cursantes a la cátedra de Economía Política, en la qual, y hora y media de la mañana y una de la tarde, se pasarán las Investigaciones sobre la riqueza de las Naciones, de Adam Smith, procurando el Maestro hacer a la nuestra las más freqüentes relaciones que sea posible. Esto en quanto se acaba de publicar la obra de Juan Bautista Say vertida al castellano, que será preferida.» (Real decreto de 5 de julio de 1807).

\title{
1. INTRODUCCIÓN
}

En los primeros años del siglo XIX adquiría presencia en España una de las teorías pioneras de la actividad empresarial, y no precisamente de la mano de un autor desconocido en España. Se trata de la obra de Jean-Baptiste Say, un autor que ha significado la cima de una literatura económica francesa caracterizada por elaborar aportaciones relevantes sobre la actividad empresarial. Es también uno de los economistas más traducidos en el panorama de la literatura económica peninsular: el más importante en dicho siglo, con 23 obras. Sus escritos fueron 
empleados como libros de texto en los años de introducción de la economía como disciplina académica y también como materia principal en los concursos de cátedra, así como referencia necesaria, y a veces suficiente, para cualquier publicación en nuestro país relativa a la ciencia económica.

Es sobradamente conocida la difusión de la obra de Say en España, aunque no así su grado de recepción. En este trabajo nos preguntamos si la influencia de la teoría del empresario de Say fue determinante. Nos interesa conocer la recepción por parte de los autores españoles de la teoría del empresario de Say, si se comprende o se ignora, si fue adaptada a la realidad nacional o si se alteró su contenido, si proviene del propio autor francés o de tradiciones anteriores o posteriores.

Una vez definida en los dos primeros apartados esta cuestión, en el tercero abordamos la difusión específica de esta teoría del empresario, tanto la ejercida directamente a través de sus traducciones, como a través de los autores españoles de textos de economía política. Ayudados por las bibliografías secundarias, considerando el marco temporal y los grupos e incentivos de recepción, podremos acotar en el cuarto apartado los autores españoles objeto de estudio. Distinguimos a los autores de este período en función de la influencia general de la obra de Say en sus textos, según lo reconocen ellos mismos y las fuentes secundarias. El apartado quinto se dedica a los autores que, elaborando sus obras en los inicios de este período, presentan un tratamiento de interés sobre la cuestión empresarial, de forma que interrelacionan distintas influencias hasta conformar los antecedentes de los autores nacidos bajo la influencia de Say. El apartado sexto presenta a los autores vinculados al pensamiento económico de Say; se examinan sus obras en busca del papel otorgado al empresario, de la importancia de su recepción y de las modificaciones o influencias que integraron. El apartado séptimo analiza el papel de la actividad empresarial en autores españoles que partieron de líneas de pensamiento lejanas a esta tradición francesa, concretamente del pensamiento ricardiano. Finalizamos este trabajo con unas reflexiones a modo de conclusiones que se han ido obteniendo a lo largo del mismo.

\section{LA TEORÍA DEL EMPRESARIO DE JEAN-BAPTISTE SAY}

La obra de Say supone un punto de inflexión en la historia de la ciencia económica, entre otras razones, por su teoría del empresario. Como ilustramos en O’Kean y Menudo (2002), el empresario es el protagonista de la obra de J. B. Say, otorgándole un lugar esencial en el sistema de formación y distribución del capital, en su concepto de innovación y de división del trabajo, en la ley de los mercados y en el sistema de distribución de rentas.

El papel de la actuación empresarial en la innovación y en sus efectos sobre la actividad económica, tan próximos al empresario schumpeteriano, la búsqueda de 
los perfeccionamientos -eliminación de ineficiencias- del proceso de producción, superando la mera administración ${ }^{1}$, las oportunidades de beneficio captadas por el empresario para dar origen a la empresa -generadas a su vez en la evolución del conocimiento y en el continuo desequilibrio entre las necesidades y la producción limitada-, la asunción de la incertidumbre provocada por el empleo productivo de los factores, todas estas funciones económicas se instalan en la teoría económica de Jean Baptiste Say, un sistema analítico creado con la ambición de explicar el conjunto de la actividad económica.

Say elabora una teoría general del empresario que permite introducir su actuación en todos los debates de la economía clásica². El punto de partida es considerar la función empresarial como un factor productivo más ${ }^{3}$, dando lugar a un concepto y esquema de producción basado en cinco factores y en su teoría del valorutilidad.

Tres son las fuentes o fondos que dan lugar a los factores de producción: industria, capital y tierra. Los propietarios de cada factor son el hombre industrioso $^{4}$, el capitalista y el propietario agrícola. Este hombre industrioso se descompone en tres agentes -sabio, empresario y obrero-, cada uno propietario respectivo de conocimiento, aplicación y ejecución. Cinco factores, con cinco

${ }^{1}$ La perfección de la producción (le bon marché) reduce costes y, a través de la loi de débouché, genera un aumento en la producción de los demás sectores. Este proceso beneficia al productor, en una primera fase, y al consumidor en última instancia, tras los efectos de la competencia: vid. Say (1828a, p. 162). Este argumento teórico, denominado teoría del valor real, es empleado en la discusión sobre la introducción de las máquinas, en la cual el empresario desempeña un papel fundamental, no sólo como instrumento de su introducción, sino también como difusor de sus excelencias. Say considera que contribuyen positivamente al bienestar económico al permitir descender el precio final del bien y liberar recursos para la creación de nuevas industrias: Say (1828a, p. 88). Aunque reconoce el peligro de retardos en este proceso, coloca al empresario como una de las llaves para la aceleración -junto al capital y al aprendizaje.

${ }^{2}$ El por qué de la aparición del empresario en Say lo encontramos tanto en un enfoque teórico construido desde la producción, como en su teoría del valor. Con un enfoque distributivo, la demanda no hubiera provocado una especial atención para la producción. Sin una teoría del valor-utilidad, la actividad empresarial no es requerida como un factor de producción diferenciado, al no precisar una condición necesaria para la producción cuya función sea la adición de utilidad en los bienes.

${ }^{3}$ Este camino permite presentar al empresario desde un enfoque funcional, dada la constante preocupación clásica por la organización social de la producción, y, además, evitar los continuos obstáculos que conlleva el análisis de este agente desde la óptica de la distribución.

${ }^{4}$ Say utilizó el concepto de hombre industrioso como un concepto que implicaba la unión del sabio, el empresario y el obrero, permitiendo introducir las capacidades en el proceso de producción, diferenciadas del capital. Se trata de un agente introducido por Turgot en los escritos de economía y mantenido por sus discípulos, con el que se pretendía diferenciar dos actuaciones -la aportación de capital a la empresa y la actividad empresarial-, hasta entonces unidas en el entrepreneur-capitaliste. Véase al respecto Menudo y O’Kean (2003). 
agentes y con cinco mercados en los cuales pueden ser adquiridos, y que permiten enlazar producción y distribución en un mismo proceso. Los propietarios de los fondos de los servicios productivos necesarios para la producción reciben un precio por su alquiler de parte del propietario, el cual proviene del bien de consumo final. En Say (1841, p. 351), esta diferencia de carácter residual entre el precio pagado por el servicio al propietario y la renta que genera la producción (beneficio) es apropiada por el empresario y retribuye la industria que él aportó. El salario de industria, el interés y las rentas agrícolas son los precios o rentas por los servicios productivos. Únicamente el salario o renta del empresario proviene de la venta de productos y no de ningún tipo de acuerdo.

Su propuesta de cinco factores de la producción permite integrar la evolución del conocimiento tecnológico y científico en la actividad productiva, y al empresario en la teoría económica como determinante del crecimiento económico, vinculando así los sistemas de producción y de distribución, y superando las figuras productivas cambiantes en favor del concepto teórico de agente económico. Pero Say también anticipa el estudio de las capacidades empresariales. Su período al frente de un negocio industrial y sus años de docencia le llevan a otorgar protagonismo a la formación y al desarrollo de las capacidades ${ }^{5}$. Éstas no sólo serán el fundamento del beneficio, sino que también se constituyen como base de la convergencia económica entre las naciones.

La obra de Say se convierte, pues, en una síntesis de ricas aportaciones precedentes con originalidades propias, que suponen una gran riqueza para la literatura de la teoría de la función empresarial. J. B. Say no constituye un caso aislado; en su mayor parte, sus contribuciones están presentes también en una serie de autores caracterizados por continuas elaboraciones teóricas que incorporan la actuación del empresario, dentro de lo que Schumpeter (1954, pp. 553

${ }^{5}$ Say pasó gran parte de su vida vinculado a la docencia, concretamente en el Conservatoire des Arts. Como describe Chassagne (1983), la formación de estos futuros empresarios abarcaba desde el conocimiento de la fabricación hasta los idiomas, pasando por estudios en casas de comercio y en clases teóricas en el Conservatoire des Arts et Métiers de París o en laboratorios de química. Say introdujo en la docencia la economía industrial, es decir, la teoría de la gestión de las empresas industriales, que no se debe confundir con la teoría aplicada a la práctica industrial o con la economía práctica, la cual es inexistente como disciplina: al respecto, véase ver Goglio (2002). Se trata de explicar cómo llevar a cabo la aplicación y su sustitución por la rutina, de tal forma que la práctica se realice desde la teoría. Esta práctica se puede llevar a cabo de forma más o menos adecuada, lo que la convierte en un arte, en el arte de la aplicación: De acuerdo con Say (1928b, pp. 157-158), «Un des objets essentiels de ce cours, est de perfectionner la gestion des entreprises industrielles [...] l'économie industrielle expérimentale, telle que je me propose de l'exposé devant vous, n'est que le résultat d'un grand nombre d'expériences, rangées suivant un ordre régulier où a chercher à connaître, par le moyen de l'analyse, pourquoi telle cause a produit tel résultat». 
y 619) calificó como tradición francesa ${ }^{6}$. Sin embargo, el empresario desaparece con esta línea de pensamiento. Por un lado, dada la trascendencia de los Principles de Ricardo, y, por otro, porque tampoco los discípulos de Say en el continente contribuyeron al protagonismo de aquél. Sin embargo, ¿qué ocurrió en España, el país de mayor divulgación de Say, a la vista de sus traducciones?

\section{DIFUSIÓN DIRECTA: TRADUCCIONES Y OBSTÁCTULOS ETIMOLÓGICOS}

Como se deduce del trabajo de Cabrillo (1978, p. 73), el número de ediciones en castellano de la obra de Say hace que no haya autor que pueda compararse en este siglo con él en cuanto a difusión directa ${ }^{7}$. Entre las claves para comprender el éxito editorial de Say está presente el empleo de sus textos en la enseñanza. Como indican Almenar y Lluch (2000, p. 111), a esto ayudó la fuerte censura, que impedía alternativas, y la gran acogida de algunos economistas, que no son seguidores suyos pero que articulan su pensamiento en torno a la obra de Say y emplean sus herramientas teóricas.

Todo esto conduce a la traducción de un gran número de obras de Say ${ }^{8}$, que nos permiten una inicial medición de su influencia en nuestro país y mostrar las

\footnotetext{
${ }^{6}$ La tradición en el estudio del empresario, que comúnmente se supone iniciada por Cantillon, tiene como cima la obra de Say. El empresario en Say ha retomado protagonismo, y su papel ligado a la incertidumbre y vinculado a una demanda dinámica muestra las huellas de Cantillon, rompiendo con la herencia de los avances de capital. Pero la influencia de Turgot también se pone de manifiesto, ya que la función empresarial se presenta inmersa en la industria del hombre, y el empresario dentro del hombre industrioso, lo cual permite a Say separar la función empresarial del capital y retomar la literatura de los avances de capital con un empresario independiente: vid. Menudo (2002).

De acuerdo con Cabrillo (1978, pp. 87-103), autores como Bastiat, con dieciseis ediciones de varias obras, Bentham con quince, G. Filangieri con seis, y James Mill con cuatro de los Elements, aún aparecen cuantitativamente lejos de la difusión de los textos de Say.

${ }^{8}$ El Traité d'Economie Politique de 1803 de Say se traduce al castellano por primera vez bajo el título de Tratado de Economía política o exposición sencilla de cómo se forman, se distribuyen y se consumen las riquezas, publicado en Madrid en tres volúmenes entre los años 1804 y 1807, y también en México en 1814. Se realizan cinco traducciones, algunas reeditadas, hasta formar ocho publicaciones en castellano del Traité a lo largo de veinte años, que cubren cuatro de las cinco ediciones aparecidas en vida del autor. También se realiza una edición de Epitome des principes fondamentaux de l'Economie politique, de 1814, como texto independiente, en 1816, seis ediciones del Catéchisme d'économie politique ou Instruction familière qui montre de quelle façon les richesses sont produites, distribuées et consommées dans la société (de 1815), bajo distintos títulos, una edición de De l'Angleterre et des anglais (también de 1816) aparecida en Madrid en 1817, cuatro ediciones de la Cartas de Say a Malthus (de 1820) y una edición del Petit volume contenant quelques aperçus des hommes et de la société (de 1817), de la tercera edición francesa de 1839, en ese mismo año. Se reproducen en castellano algunos artículos, caso de «Ensayo histórico sobre el origen, progreso y resultados probables de la soberanía de los ingleses en la India» y «Disertación sobre la balanza de los consumos y las producciones», ambos aparecidos en Mercurio de España, en diciembre de 1824 y marzo de 1825 respectivamente.
} 
desviaciones u omisiones, al realizar un estudio comparado de la traducción con el original. También podemos medir su influencia por medio de variables temporales como los retardos o períodos entre traducciones, a la manera de Carpenter y Redlich (1973). En un esquema temporal, podemos apreciar que no existe dilación en la aparición de la primera obra de carácter económico de Say en España, a diferencia de otros países -Alemania o Estados Unidos- donde su influencia también fue relevante ${ }^{9}$. Si bien el espacio entre la primera y la última edición es de unos treinta años, la influencia de Say en España es especialmente intensa durante los veinte años que median entre 1814 y la mitad de la década de los treinta.

Ya en las publicaciones de J. B. Say en castellano podemos encontrar una serie de obstáculos a la difusión de sus ideas económicas. La intensidad en la edición de traducciones entre los años 1814 y 1827 pudo convertirse en saturación e impedir la recepción de su obra más importante, el Cours complet (1828a), que, en el caso de la teoría del empresario, supone la inexistencia en castellano del texto más completo de J. B. Say sobre este tema. Esto no significa, sin embargo, que esta teoría esté ausente en las obras en castellano de este economista francés. La calidad de la traducción también supuso un obstáculo, aunque se fue mitigando a lo largo de las distintas ediciones, como se indica en Menudo (2002). Las primeras traducciones, tanto del Traité como del Catéchisme, fueron negativas para la difusión de la teoría del empresario. La primera y peor traducción del Traité se realiza entre 1804 y 1807 por José Queipo de Llano. Encontramos que el término empresario es substituido por los de maestro u oficial; en otros casos se limita a eludirlo, sin tratar de reemplazarlo por ningún otro concepto. En el caso del Catechisme (1815a) aparecen dos ediciones en 1816 de desigual calidad. Agustín Pascual es muy fiel al original, mientras que la versión de Cesáreo María Saenz elimina al empresario y sitúa en su lugar al director de una industria fabril en unos casos, al fabricante en otros: vid. Say (1816c, p. 18).

Pero más allá de la calidad de la traducción, estamos ante un obstáculo lingüístico que estos primeros traductores españoles y otros posteriores no supieron resolver. El vocablo entrepreneur ${ }^{10}$, esencial en la obra de Say y ausente de

\footnotetext{
${ }^{9}$ Las traducciones aparecidas en Inglaterra fueron escasas, tan sólo una edición del Catéchisme (en 1816), una del Traité (en 1821), dos de Lettres à Malthus (ambas en 1821) y dos de De l'Angleterre et des Anglais (ambas también en 1816).

${ }^{10}$ El término entrepreneur no aparece definido en Francia hasta la aparición del diccionario de Furetière de 1690: "Celui qui entreprendre. Il se dit premièrement des Architectes qui entreprennent des bâtiments à forfait. L'entrepreneur de la fonction des mers s'y est enrichi. On le dit aussi des autres marchés à prix fait. On a traité avec un entrepreneur pour fournir l'armée de vivres et des munitions». Hay que esperar hasta el Dictionnaire universel du commerce de Savary des Bourlons de 1741, para encontrar el uso del vocablo vinculado a diferentes actividades económicas, y hasta la segunda mitad de siglo para el empleo generalizado del término en las obras de economía.
} 
los diccionarios de castellano del siglo XVIII y principios del siglo XIX, constituye una barrera etimológica particular, aunque no así los lexemas industria o industrioso, con cuyo uso veremos a los autores españoles mucho más cómodos ${ }^{11}$. Estos últimos buscaban alternativas a empresario, un registro quizá de escaso uso, que no es recogido por los diccionarios de la Real Academia Española hasta mediados del XIX, pero que no estaba del todo ausente, como demuestra el Nuevo diccionario francés-español de Antonio de Capmany (1817, p. 336), al traducir entrepreneur como «empresario, asentista: el que emprende una obra por un tanto, ó por cierto precio». Las alternativas difieren mucho del significado expresado por entrepreneur, como pone de manifiesto el Diccionario de la lengua castellana (1791) de la Real Academia Española. Tanto el vocablo fabricante -«El dueño, maestro, ó artífice que tiene por cuenta la fábrica de alguna cosa, ó trabaja en ella»-como el de maestro -«el que sabe o enseña cualquier arte o ciencia»-, u hombre de negocios - «el arrendador de rentas, provisiones y abastos, y el que trata en letras de cambio»- nos conducen hacia acepciones completamente diferentes.

Sin embargo, las traducciones son tan sólo uno de tantos mecanismos de difusión de ideas. Para valorar la influencia de la teoría del empresario de Say debemos indagar en los autores españoles de un período que abarca la primera mitad del siglo XIX.

\section{PRECEDENTES: LAALARGADA SOMBRA DE CANTILLON, LOS INDUSTRIALISTAS Y ADAM SMITH}

Mientras que la etapa inicial de emergencia de la economía como materia académica en nuestro país (1776-1806) estuvo marcada por la influencia de Adam Smith, la aparición de la economía como disciplina universitaria trae consigo la apertura de «la era de Say en España», en palabras de Martín Rodríguez (1989, p. 40). El Traité d'économie politique (1803) se publica en castellano justo antes de la Guerra de Independencia ${ }^{12}$ y se adentra en la escena española con el eminente

\footnotetext{
${ }^{11}$ Este concepto de industria del hombre no se limita a la ejecución de una tarea, sino que engloba la propiedad del capital humano acumulado necesario, por lo cual es también fuente independiente de riqueza: vid. Allix (1910). Los diccionarios de lengua castellana recogen esta acepción de saber práctico durante todo el siglo XVIII; así, el Diccionario de la lengua castellana de 1791, que la define como «destreza o habilidad en qualquier arte».

${ }^{12}$ La obra de Say es conocida en España incluso antes de su temprana traducción. Juan López de Peñalver, en el Mercurio de España, presenta la obra en dos números (15 y 31 de marzo de 1804). También recoge la prensa la aparición de la primera traducción al castellano de Say, concretamente en Efemérides de España (viernes 1 de febrero de 1805), donde se reproduce el discurso preliminar del Traité en castellano. En ambos casos se hace referencia a la importancia de la difusión de la economía política por su carácter positivo y «para no quedar entre los comerciantes».
} 
protagonismo que le otorga el plan de estudios de Caballero. Su influencia directa por medio de sus traducciones se extiende desde 1804 hasta 1846, sin retraso apreciable alguno y con un período de gran intensidad entre los años 1814 y 1827.

Una vez finalizado el período bélico, autores españoles empiezan a publicar textos de carácter económico. Como señalan Almenar y Lluch (2000, p. 105), inicialmente son obras de carácter didáctico, aunque sin afán de convertirse en libros de texto, ya que, con la restauración de la vida académica y de las cátedras de economía, éstas emplearán sistemáticamente el Traité de Say ${ }^{13}$.

Estos primeros textos manifiestan un claro sustento en la obra de Adam Smith o en la de economistas preclásicos, siendo la mayor parte de los autores conocedores de la obra de Say. Si bien existen receptores de Adam Smith de una forma tan nítida que mantienen la marginación de la actividad empresarial deparada por el maestro escocés ${ }^{14}$, entre los españoles encontramos también concepciones preclásicas que abren un lugar a la misma, junto a desviaciones teóricas que permiten la inclusión de la función empresarial.

Así, Domingo de las Heras (1813) concibe la producción como un proceso dinámico, lo que le lleva a presentar un conjunto de actuaciones ligadas a ésta y cuya existencia es imprescindible para lograrla, de manera que no dependa sólo

${ }^{13}$ Hasta 1846, sus obras son empleadas como manuales en los distintos ámbitos de enseñanza de la economía política, ya sean de naturaleza pública o privada, y orientados tanto a futuros cargos públicos como a funcionarios o a comerciantes, de acuerdo con Martín Rodríguez (1989). El Tratado es introducido como libro de texto en la Cátedra de economía civil y comercio de la Real Sociedad Económica Aragonesa por su titular en 1807, José Benito de Rivera, y continuará durante el magisterio de Agustín Alcaide (1815-21). Los consulados y juntas de comercio también se convierten en centros de enseñanza, con sus propias cátedras y teniendo a Say como referencia. La Cátedra de economía política de la Junta de Comercio de Barcelona nace de la mano de Jaumeandreu (1814) y también tiene como primer libro de texto de Say, al igual que sucede en la Junta de Málaga, donde Manuel María Gutiérrez, artífice de la traducción más importante del Traité y de su prólogo más afamado, es el catedrático de comercio y economía política. En la misma línea, la Cátedra de la Sociedad Económica Matritense se reestablece en 1820 con José Antonio Ponzoa al frente, el último traductor del Traité, obra que forma parte incluso del concurso de cátedra.

${ }^{14}$ Ramón Lázaro de Dou ha sido considerado -por Almenar y Lluch (2000, p. 108)- como uno de los vehículos más importantes de la difusión del pensamiento de Adam Smith en España. La influencia de Say sobre él es inexistente, si bien es cierto que conocía su obra, al poseer un ejemplar del Traité en su biblioteca: vid. Lluch (1973, p. 190). El objeto de su obra es la difusión de Adam Smith, y su contenido constituye una guía de La riqueza de las naciones, con múltiples citas que se extienden hasta casi la totalidad de los capítulos. Aunque no existen referencias a su aplicación en España, Dou no se limita a reproducir los principios del autor escocés, realizando una crítica mercantilista de la obra. Lázaro de Dou y Bassols constituyen importantes muestras de la desvinculación total del empresario con relación a la actividad económica, al no hacer referencia alguna a la actividad empresarial o a figuras productivas vinculadas a la producción, ni tan siquiera en aspectos como la división del trabajo. Se trata de claros ejemplos de las consecuencias que para la teoría del empresario tuvo la casi trascripción de una obra -Wealth of Nations- que margina la actividad empresarial. 
de la obtención de capital. Pero sus planteamientos y su problemática preclásica ${ }^{15}$ no conllevan cuestiones referentes al efecto de estas actuaciones empresariales fuera de la organización de la producción. No hay mercados de factores aunque existe el factor trabajo, ni monopolios originados por la innovación, aunque se producen invenciones reductoras de costes. Intuye la necesidad de una teoría del empresario, pero en ningún momento hace uso de la teoría de Say, limitándose a situarse en planteamientos o escalafones cercanos a Turgot ${ }^{16}$, si bien hace depender la necesidad de la actuación empresarial de la existencia de una unidad dinámica denominada taller, fábrica o empresa.

En opinión de Almenar y Lluch (2000, p. 107), Gonzalo de Luna ${ }^{17}$ supone un acercamiento a la economía clásica, al entrever problemas en el concepto de producción de Smith. Desde una teoría del valor subjetivo, se concibe la producción como una acomodación de los productos físicos a la demanda, lo cual le invita a incorporar innovaciones de productos, de procesos, y perfecciones en el proceso de producción, como alternativa a una demanda en constante cambio. Sin embargo, no es capaz de presentar un agente identificado con estas actuaciones ${ }^{18}$. Para nuestro objeto de estudio resulta de especial interés el uso que hace de las apli-

${ }^{15}$ Domingo de las Heras sigue la obra de Ward en cuanto a la temática tratada, pero con algunas diferencias. El Proyecto económico de Ward (1779) tiene dos partes, la primera dedicada a la economía española y la segunda a la economía colonial. Domingo de las Heras sustituye la segunda parte por contenidos más acordes con los problemas de la economía española de comienzos del siglo XIX, pero mantiene el mismo esquema organizativo. Ward empieza por una «Vista general del reino», que Heras denomina «Economía estadística», y continúa con la población y los sectores económicos.

${ }^{16}$ Como señala Fontaine (1989), en Turgot la función empresarial aparece inmersa en el concepto de avance de capital, dentro del cual no se diferencia la función empresarial de la aportación de capital. Sin embargo, la función del empresario existe y se presenta como la industria del hombre -un factor de producción más-, abarcando la captación de oportunidades de beneficio como diferencia de precios, la coordinación y la localización de la producción. Desde la distribución, la actuación empresarial permanece independiente de los demás factores, al distinguir el salario de industria del empresario de la retribución del capital. Esta diferenciación conduce a Turgot a definir al hombre industrioso como el agente que aporta su industria con independencia del factor capital, con lo cual la función empresarial se distingue del capital, algo que no se produce en su concepto de empresario. Al respecto, véase Menudo y O’Kean (2003).

${ }^{17}$ La obra de carácter económico de Gonzalo de Luna está compuesta por: Diferencia que hay entre la Estadística, Economía política y Aritmética Política (1819), Ensayo sobre la investigación de la naturaleza y causa de la riqueza de las naciones relativamente a España, o sea, la economía universal teórica aplicada a la nación española (1819-20), y Pensamientos de Economía-Política ó policía pública (1820). Esta última obra es, a nuestro entender, desconocida para la historiografía económica.

${ }^{18}$ No hay en él agentes económicos, ni un factor vinculado a una función empresarial independiente, ni desde el análisis distributivo ni desde el productivo. Sin embargo, sí presenta un concepto similar al sabio, quien genera el conocimiento que permite la innovación y los perfeccionamientos, pero no especifica el proceso de incorporación a la producción. 
caciones innovadoras en la producción como ejemplo de la vinculación del conocimiento con la producción, así como la emergencia de un concepto de producción lejano de la reproducción clásica, y cercano a las condiciones de la demanda. El intento de Gonzalo de Luna no es crear un sistema teórico: de ahí que no vincule estas actuaciones con un agente específico que permita ordenar los conceptos, conformándose con referencias a figuras productivas a modo de ejemplos.

En la obra de José Canga Argüelles [1825], el protagonismo de una demanda dinámica le permite concebir la producción como algo más que la adición de capital, tierra y trabajo. Se genera así una gran riqueza de conceptos dentro de la producción, tales como el cálculo apriorístico, la adaptación a la demanda, la innovación de productos y el conocimiento de las necesidades del mercado ${ }^{19}$. Incluso intuye la existencia de un beneficio independiente de las rentas de los tres factores clásicos, si bien no está vinculada con la actuación empresarial. Sin embargo, como señalan R.S. Smith (1968, p. 319) y Almenar (1997, p. 152), a pesar de conocer soluciones teóricas, Canga no es capaz de independizar la actuación empresarial del trabajo, algo que le impide solucionar el problema de ubicación de ese beneficio tan magníficamente intuido ${ }^{20}$. Una vez más estamos ante fases preliminares a la teoría del empresario de Say, aunque en este caso Canga parece tener un buen conocimiento de la obra del autor francés.

Pero la influencia de Smith se entremezcla con otras obras de especial relevancia para nuestro objeto de estudio. Por un lado, la alargada sombra de Cantillon, y, por otro lado, la de los industrialistas, de los cuales el mismo Say también es impulsor y referencia. De acuerdo con Estapé (1971), desde Jovellanos hasta la primera traducción íntegra -Fuentes de la riqueza pública (1833)- de Antonio Domingo Porlier, pasando por las Lecciones (1779) de Danvila y Villarrasa, la obra de Cantillon perdura en el tiempo en nuestro país ${ }^{21}$. A estas influencias directas

${ }^{19}$ Esta preeminencia de la demanda fundamenta sus políticas de liberalización de la mano de obra y de procesos productivos que incorpore la adaptación, la supresión de empresas públicas por su escaso dinamismo y un largo etcétera. Véase Comín (2000).

${ }^{20}$ Únicamente enriquece el concepto de trabajo al denominarlo industria del hombre, pero esto invita a la posterior simplificación, vinculando trabajo con ejecución y desapareciendo cualquier pista de la función empresarial, y sin referencias al empresario.

${ }^{21}$ De acuerdo con Estapé (1971, pp. 79-85), Bernardo Danvila y Villarrasa es el canal de mayor difusión de Cantillon en nuestro país. Sus Lecciones de Economía Civil (1779) se convierten en un importante instrumento de difusión, aunque no de calidad, al menos en cuanto a la relevante aportación a la función empresarial de Cantillon. El empresario no existe en la obra de Danvila, y la incierta naturaleza del beneficio no define una clase social, como en el sistema de Cantillon. La industria del hombre se presenta como requisito para la producción, junto al trabajo, el capital y la ciencia, pero sin definir su contenido. Junto a labradores, comerciantes y artesanos, aparecen los directores, quienes proporcionan ciencia a la producción. Esta industria, la incorporación del conocimiento y la referencia a las ganancias inciertas de los trabajadores por cuenta propia, constituyen su únicas menciones de la función empresarial. Sin embargo, serán importantes para entender algunas desviaciones de los autores españolas vinculados a la obra de Smith. 
sumamos la difusión indirecta de otros autores como Condorcet, Genovesi y Canard $^{22}$.

De la misma forma, existe un grupo de autores calificados por la literatura secundaria con el apelativo de industrialistas. Textos que se alejan de la economía política clásica y que, tomando como referencia a Chaptal ${ }^{23}$, Babbage, Dupin y Canard, intentan promover en el seno de la sociedad el desarrollo máximo de la industria ${ }^{24}$. Siguiendo a Lluch (1992), se trata de obras orientadas a problemas específicos, con una metodología heredera de la aritmética política, como las $R e$ flexiones sobre la variación del precio del trigo [1812] de Juan López de Peñal$\operatorname{ver}^{25}$, o de trabajos que tenían por objeto promover medidas de política económica ligadas a la difusión de la industrialización, caso de España con industria fuerte y rica (1816) de Antonio Buenaventura Gassó, o los artículos de Josep Andreu Fontcuberta. En cada una de estas obras, el papel del empresario es sorprendentemente menospreciado si tenemos en cuenta la importancia de la actividad industrial y de los nuevos acontecimientos ligados a ella -innovaciones, grandes organizaciones industriales y concentración de la mano de obra- en estos momentos históricos, y el papel otorgado por Chaptal al empresario adquiere una considerable relevancia en su principal obra De l'industrie française $(1819)^{26}$.

${ }^{22}$ El primer traductor de Say (1804-1807, p. 14) comenta que tenían previsto traducir a Canard antes de la aparición del Traité, pero que su obra es una memoria sobre un punto particular y no general de la economía, e incluye fórmulas algebraicas que perjudican su lectura y la hacen «desagradable a los lectores y a los hombres con talento que no conocen los elementos del álgebra». Esta obra fue presentada en España por Juan López de Peñalver en su artículo «Principios de Economía política de Canard: premiado por el Instituto Nacional», en Mercurio de España (1801, abril), considerando que «lleva á un punto de perfección la ciencia de la Economia política, qual nunca había tenido». Cfr. Lluch (1992, p. 57).

${ }^{23}$ Las obras de Jean-Antoine Chaptal (1756-1832) se traducen con escaso retraso respecto a las ediciones originales; las de carácter teórico se publicaron en Madrid, y las referidas a innovaciones tecnológicas en Cataluña. Vid. Bolado (2001). Su obra económica más relevante, De l'industrie francaise (1819), fue la que mayor retraso registró en su traducción española: Tratado de la industria francesa. Traducido y compendiado, é ilustrado con algunas notas por D. José Zorrilla de S. Martín. Madrid, Amarita, 1834. No obstante, se habían publicado en 1819 extractos en Mercurio de España (abril-junio).

${ }^{24}$ Véase Almenar, Argemí y Lluch (1999, p. 1.436).

${ }^{25}$ López de Peñalver es uno de los autores más importantes de la primera mitad del siglo XIX en España, tanto por su actividad política como por su aportación científica, como pone de manifiesto el trabajo del profesor Lluch (1992). Buen conocedor de la economía política clásica, desde Smith a Say, López de Peñalver toma como fuentes intelectuales a las obras de Steuart, Chaptal y Canard, para, al decir de Almenar y Lluch (2000, p. 105), convertirse en una de las cimas del análisis económico en España. Sin embargo, López de Peñalver no considera que la economía política sea una ciencia, y de hecho favorece en lo posible la sustitución de las cátedras de economía por las de ciencia aplicada.

${ }^{26}$ Chaptal dedica el segundo capítulo de la parte cuarta de su obra, titulado De la Conduite du fabricant et de son influence sur l'industrie, a la problemática de la dirección de la fábrica. Sin referencias al empresario, sino tan sólo al director y al fabricante, Chaptal presenta una serie de 


\section{LA ORTODOXIA ES JEAN-BAPTISTE SAY}

Es aquí donde iniciamos el análisis de los autores que reconocieron tener como referencia a J. B. Say, y que así han sido considerados por Martín Rodríquez (1989) o por Almenar y Lluch (2000). Vinculados a la docencia, elaboran sus obras mientras imparten o se imparte el Traité en las aulas, y con el objeto de presentar una alternativa al economista francés, por medio de novedades en la estructura del tratado o bien a través de adiciones, mediante la incorporación de análisis relativos a economía nacional. Bajo la forma de manual, el objetivo es diferenciarse de Say pero sin distanciarse demasiado, ya sea por miedo al vacío teórico o por miedo a ver cerradas ante sí las puertas de unas aulas cuya docencia era en buena medida descendiente doctrinal de sus obras.

El primer autor a destacar es Casimiro de Orense, que representa un claro ejemplo de la necesidad de integrar la obra de Say en un análisis fundamentado en doctrinas precedentes ${ }^{27}$. La evolución en el pensamiento de Orense permite presentar la figura del empresario con valores de modernidad en el análisis teórico, en Orense (1820), frente al antiguo capitalista cultivador de Turgot. Por ese camino, y en la misma obra, encontramos un ejemplo de la introducción del pensamiento de Say en esquemas anclados en la fisiocracia, con los consiguientes problemas teóricos y con una clara manifestación de la necesidad de una evolución teórica que supere la primacía agrícola, ejemplificada en este caso con la inclusión del empresario.

Con Eudaldo Jaumeandreu hablamos ya de textos que tienen como base teórica a J. B. Say, si bien en este caso se propone una temprana respuesta a la economía clásica desde la perspectiva industrial ${ }^{28}$. Jaumeandreu orienta sus pasos

funciones productivas originadas por la existencia de una demanda dinámica y de una evolución constante del conocimiento. La organización de la producción aparece como consecuencia de la existencia de necesidades y de una comparación entre precios. Se origina así el requisito de una función de dirección que se lleva a cabo por medio de una constante incorporación de conocimientos técnicos ante unas necesidades que obligan a revisar el proceso productivo en busca de su perfeccionamiento. Hay una función empresarial no nacida de la explicación del beneficio, ni de las innovaciones, sino de los constantes desequilibrios originados por la demanda y por el conocimiento, en Chaptal (1819, II, p. 229). Son ideas vinculadas a la eliminación de ineficiencias, no sólo en la organización interior de la producción, sino también de una forma similar en la localización de la unidad productiva. La actividad empresarial queda distinguida del capital, pero lejos de cualquier intento de sistematización en un esquema de factores de producción clásico.

27 Véase López Castellano (2000).

${ }^{28}$ El profesor Lluch (1988, p. 8) sostiene que esta obra es también un texto de carácter político: concretamente, que se trata del espejo de la revolución burguesa, con una defensa del proteccionismo económico y de la libertad política. Desde el punto de vista económico, algunos comentaristas, como Perdices (2000, p. 273), consideran que Jaumeandreu intenta «adaptar el pensamiento smithiano a España al igual que lo había hecho Say para Francia». Sin embargo, no consideramos que su objetivo en los Rudimentos [1816] fuese éste, como Jaumeandreu mismo menciona en el prólogo, y ni tan siquiera vemos en él rastros de la obra de Adam Smith. 
hacia esquemas cercanos a los de Flórez Estrada y a los clásicos británicos, pero manteniendo un contenido asentado en la obra de Say ${ }^{29}$. Sin embargo, aquellos aspectos menos relevantes para el autor catalán, caso de la teoría del empresario, se van difuminando hasta desaparecer. La estructura de la teoría de la producción de Say se mantiene, aunque más en la forma -teoría de la industria- que en el contenido, en el cual el empresario es sustituido por el director de industria. El empresario de Say no existe en la obra de Jaumeandreu en ningún momento, aunque perviven algunas actuaciones empresariales que mantienen un papel fundamental en el esquema teórico -innovaciones y perfeccionamientos ${ }^{30}$-, si bien más cercanos al capital que al empresario. La Cataluña dinámica sobre la que Jaumeandreu fundamentó su argumentación analítica pudo tener necesidades de capital, de expansión de la demanda, de incorporación de innovaciones, pero no de iniciativas empresariales. Para Jaumeandreu, el empresario no es un obstáculo al crecimiento y su actuación no se presenta como un problema económico.

Un segundo autor de gran trascendencia para la enseñanza de la nueva ciencia es José Espinosa de los Monteros (1831), quien toma como referencia al Say menos claro y menos sólido ${ }^{31}$, empleando una estructura desordenada y, en algunos casos, incoherente $^{32}$. Sin embargo, la influencia de Say en su obra es nítida y exclusiva. La teoría del empresario es difundida en parte, desde el punto de vista teórico, y en absoluto desde las aplicaciones teóricas de Espinosa a la realidad española. La presentación de la función empresarial como factor independiente, su inclusión en la reproducción del capital, o la relevancia de los continuos perfeccionamientos como

\footnotetext{
${ }^{29}$ Véase Martín Rodríquez (1989). La influencia de Say en su obra parte de la elección del Traité d'économie politique como libro de texto en su cátedra, hasta sustituirlo por sus propios Rudimentos en 1816. Posteriormente Jaumeandreu nos revela que su primera obra era tan sólo un libro de texto sin más pretensiones que la difusión de la economía política, mientras que su Curso elemental (1836) sí pretende elaborar una teoría crítica con la ortodoxia, acusándola de partir de las falsas bondades del libre comercio exterior: vid. Jaumeandreu (1836, p. iv). En este momento se integran nuevas influencias añadidas a la de Say, como las de Smith, Flórez, Herrenschwand y Sismondi -señaladas por Martín (1989, p. 50)-, y Cantillon -por Estapé (1971, pp. 84 ss.).

${ }^{30}$ La mayor parte de estos autores emplean la teoría del valor real de Say para apoyar la introducción de tecnología en la producción.

${ }^{31}$ Espinosa toma como referencia la primera edición del Catéchisme (1815). Es importante reseñar que Say publicó tres ediciones en vida de esta obra (1815, 1821 y 1826), con grandes diferencias que ponen de manifiesto la evolución del pensamiento de su autor: vid. Steiner (1996, p. 40). Entre la primera y la segunda edición las diferencias son sustanciales: Say amplía su pensamiento sobre la teoría de la producción -de cinco a ocho capítulos- y su teoría de la distribución -de tres a seis-, con lo cual la obra se amplía en un tercio al aparecer nueve capítulos más -los 6, 7, 9, 10, 17, 19, 20, 25 y 29- y desaparecer los capítulos «Des colonies», «Des revenus fondés sur les produits matériels», $\mathrm{y}$ «Du prix réel et du prix nominal des choses», cuyas materias se tratan en otras secciones. La tercera edición no difiere en grandes aspectos de la segunda, y tan sólo incorpora algunas notas más: véase Steiner (1996, p. 40). Para una mayor profundidad en la evolución del pensamiento de Say a lo largo de su obra, véase Steiner (1998).

32 Tal es la consideración de Martín Rodríguez (1989, p. 61).
} 
parte de la función empresarial, son conceptos presentes en la obra de Espinosa y relevantes en un sistema económico orientado hacia la producción ${ }^{33}$. Sin embargo, el retorno a una división tripartita de los factores de producción tiene unos costes muy altos, pagados con la desaparición de las innovaciones, la incoherencia de presentar tres mercados para cuatro factores, o la existencia de funciones económicas sin correspondencia con los factores. Tan sólo hay lugar para las capacidades y el conocimiento como determinantes de la actuación empresarial.

El Marqués del Valle Santoro opta por tomar una alternativa a Say que permita introducir una novedad en cuanto al contenido y en cuanto a la forma, pero sin alejarse del autor francés ${ }^{34}$. La alternativa la constituyó K.H. Rau, y funcionó editorialmente ${ }^{35}$. En lo que a nuestro objeto de estudio interesa, la actuación empresarial desaparece como factor de producción independiente aunque continúe en escena el empresario de industria, esta vez aportando trabajo y vinculado al capital. Su análisis es indicativo, lo cual le plantea difíciles cuestiones teóricas que le obligan a caer en continuas contradicciones. Valle Santoro se separa de la teoría de la producción de Say, del concepto de empresario y de la teoría de la distribución, y toma como referencia a Rau, pero sin ser capaz de trasladar su contenido ${ }^{36}$. Tan sólo encontramos actuaciones empresariales aisladas en el sistema teórico expuesto que abordan problemas anteriores al propio Say, como la coordinación o la intermediación, y que nunca han sido independizadas del capital. Valle Santoro adopta planteamientos más cercanos al concepto de empresario de Rau que al de Say, si bien estas dos últimas teorías no son independientes ${ }^{37}$.

${ }^{33}$ Véase Almenar (1997, p. 162).

${ }^{34}$ Blanqui (1945, p. 712) menciona una traducción al francés de los Elementos de Valle Santoro, pero no la fecha de edición, y hace referencia a un solo volumen, de lo cual podemos deducir que tan sólo se traduce la primera parte. Blanqui califica la obra como «excellent ouvre élémentaire, quelquefois un peu obscure».

35 Véanse Martín Rodríguez (1989, p. 51) y Perdices (2000, p. 288).

${ }^{36}$ Sigue el esquema presentado por Rau, pero con menos riqueza para nuestro objeto de estudio. El beneficio se define como la diferencia entre las rentas y el valor final, y retribuye «les peines et les risques de son entreprise». Pero Rau se plantea si el beneficio del empresario es una renta de la empresa o si es un salario, distinguiendo entre quienes lo consideran un salario -Canard y Say-, un alquiler del capital -Smith, Ricardo, Lotz, McCulloch-y un precio del empleo del capital -Sismondi, Jacob. Rau (1839, pp. 208-209) prefiere considerarlo como una renta especial procedente de una unión íntima entre el trabajo y el capital, en la que no puede distinguirse la parte de uno y de otro, uniéndose a otros autores como Storch, Ganilh y Hermann.

${ }^{37}$ Aunque las referencias de Rau son extensas, está muy influenciado por Say: de hecho, Karl Marx lo consideró el Say alemán. Ello se constata en su obra, en la que hay continuas citas del autor francés, en el empleo de conceptos de éste -servicios productivos, agentes de la producción- y, sobre todo, con la introducción del empresario, tanto en la producción como en la distribución, parte en la cual dedica un capítulo a la ganancia del empresario (Unternehmer). Schumpeter (1954, p. 619) considera que la función empresarial se mantiene constante gracias a Rau y hasta la obra Die Lehre vom Unternehmergewinn [1855] de Hans von Mangoldt (18241868), la siguiente gran aportación a la función empresarial tras Say. 
Podríamos decir que la teoría del empresario de Say sufre un filtro -la obra de Rau-, que da lugar a un esquema de conceptos más cercanos a las ideas de Turgot o Baudeau ${ }^{38}$, pero para un escenario industrial, y que supone un paso atrás en el desarrollo de la teoría del empresario.

La Revista general de la economía política (1835) de Mariano Torrente tenía por objeto servir como manual de texto «en las cátedras de Economía política». Mariano Torrente también busca una referencia teórica alternativa, en este caso Melchiorre Gioja ${ }^{39}$, aunque va mucho más allá y, al decir de Almenar y Lluch (2000, p. 126), se acerca a los límites de la traducción. En su obra, otorga el papel protagonista de la actividad económica al empresario y a su actuación. Perfectamente diferenciado del capital, el empresario es el centro de la distribución, y la función empresarial es determinante de la producción. Sin embargo, el empresario y su actuación no están relacionadas de forma adecuada, hasta el punto de no encontrarse mención de él al hablar de la producción, aunque su actuación está presente. La importancia fundamental de la obra viene de la eliminación del protagonismo del capital y la inclusión de nuevos escenarios, en los cuales hay lugar para la actuación empresarial. Un concepto dinámico de la actividad económica, la importancia del conocimiento, la coordinación, la incertidumbre o la innovación son elementos vinculados a la producción. Pero Mariano Torrente abandona el esquema de cinco factores de producción, de tal forma que, cuando los requiere -al hablar de la distribución-, no es capaz de explicar el origen del beneficio aunque mantenga su existencia ${ }^{40}$. La causa es que no considera como un problema la insuficiencia de factores, porque el

${ }^{38}$ Baudeau (1771, p. 694) considera que cualquier actividad productiva puede realizarse de dos formas muy diferentes, individualmente -en petit- o de una forma colectiva -en grand. La diferencia entre estos sistemas la constituye la existencia o no de un jefe de explotación.

${ }^{39}$ Nuovo Prospetto delle scienze economiche (1815) de Melchiorre Gioja es una obra que, según su autor, sigue la estructura clásica en cuanto a la teoría -producción, distribución, consumo, acción gubernativa-, pero que diferencia una parte práctica o aplicada -la III, pp. 139-245, sobre «applicazione delle teoria economiche alla stima de' fondi»- totalmente independiente de la teoría y obviada por Torrente. Mariano Torrente no persigue la traducción de la obra de Gioja, más bien desea crear un texto propio, aunque para ello emplee la traducción literal del autor italiano. Su sección dedicada a la producción, desde el capítulo 4 de la primera lección hasta la lección 16 incluida, consiste en una traducción literal de los libros 1 y 2 de Gioja. El libro 3 de Gioja -«Combinazioni binarie ternarie quaternarie [...] de’ mezzi d'economia»- describe los sectores económicos, pero Torrente lo sustituye por siete lecciones -las 17 a 23- sobre la influencia de la intervención estatal en la actividad económica, que no son originales, sino una traducción del libro primero de la cuarta parte - «acciones gubernativas sobre la producción, distribución y consumo de la riqueza». En la parte dedicada a distribución, Torrente empieza con un capítulo introductorio que Gioja no contiene y, por lo demás, continúa tomando todo el contenido de forma más o menos literal del Nuovo Prospetto.

${ }^{40}$ Mariano Torrente traduce este capítulo de Gioja pero con modificaciones, tanto en su estructura como en su dimensión, aunque el contenido es el mismo. Gioja divide el capítulo en dos partes más un cuadro final, mientras que Torrente lo divide en tres más un cuadro final idéntico. El autor español tomó el primer capítulo de Gioja, de carácter general o teórico 
capital se reproduce en la empresa y el empresario siempre existe. Únicamente se requiere conocimiento, para lo cual aboga por una red de instrucción formada por academias, universidades, escuelas o formación en el extranjero.

También hay autores cuya producción científica no se limita casi exclusivamente a la elaboración de manuales, aunque su actividad haya estado vinculada a la vida académica. Es el caso de Manuel María Gutiérrez, quien conoce perfectamente la obra de Say, referente obligado en todas sus exposiciones. Este conocimiento se plasma en un protagonismo importante por parte del empresario en sus primeros escritos, sin bien quedan lagunas importantes que separan al empresario del resto de la teoría económica ${ }^{41}$. El empresario desaparece cuando se centra en la problemática del librecambio ${ }^{42}$, aunque este tema, fundamental en la obra económica de Gutiérrez, podría permitir la aparición del empresario en multitud de aspectos. Si bien se discute la obra de Say de forma minuciosa, y aunque el autor presenta análisis históricos de desarrollos industriales -en las páginas 89 a 140-, no hay lugar en sus textos para el empresario y tampoco para sus actuaciones. El empresario no es importante para este autor, como así lo revela su traducción de una obra que hace desaparecer al empresario -Elements of Political Economy de James Mill-, sin que esto suponga ningún comentario por su parte ${ }^{43}$.

-«Elemento común a toda empresa»- y lo divide en dos partes, con lo cual queda prácticamente idéntico. La segunda parte de Gioja es una aplicación particular que analiza el beneficio en cada sector -con una sección para cada uno de ellos-, que Torrente sustituye por una crítica a Flórez y ejemplos, no tomados de Gioja, de cómo separar el beneficio en cada actividad económica. Sin embargo se pierde mucho en el resumen, porque Gioja busca la delimitación del beneficio para cada sector. En la agricultura analiza los clásicos casos del aparcero, colono y propietario-cultivador; en la empresa de arte se limita a presentar las diferencias respecto a la empresa agrícola, y en el comercio define los determinantes del beneficio. Finalmente -II, pp. 195-212-, el autor italiano presenta un caso real en el cual los conceptos analizados podían contribuir a aclarar un problema judicial.

${ }^{41}$ Gutiérrez (1819, p. 23).

${ }^{42}$ En 1819, Gutiérrez empieza a distanciarse de la teoría de libre comercio exterior de Say, con una de sus proposiciones en los exámenes que empezaba afirmando que «Son tan funestas como brillantes las teorías de Mr. J.-B. Say sobre la libertad del comercio...», y continúa con un informe de 1821 sobre la conversión de Cádiz en puerto franco, elaborado para el Consulado de Málaga, en el que rechaza esta posibilidad sobre la base de una doctrina proteccionista. Al respecto, véase Grice-Hutchinson (1982, p. 163). Sin embargo, su primera publicación de marcado carácter proteccionista es el artículo «Economía política. Algodones» (1828), aparecida en el Correo Literario y Mercantil (5 de diciembre), donde defiende la protección de los agricultores algodoneros de Motril frente a una industria catalana tachada de monopolista: Sobre el particular, vid. Velasco (1990, p. 93).

${ }^{43}$ Con la traducción de los Elements de James Mill en 1831, Gutiérrez (1831, p. 4) explica que el motivo de la edición es la necesidad de una alternativa a Say, por ser éste demasiado minucioso y prolijo. James Mill hace desaparecer al empresario y lo sustituye por el capitalista, al igual que los cinco factores de producción, que pasan a ser capital y trabajo, sin ningún comentario por parte de Gutiérrez, algo que sí hace en relación con la teoría ricardiana de los costes comparativos. Vid. al respecto Grice-Hutchinson (1982, p. 165). 
La influencia de Say provoca una línea de pensamiento que será ortodoxia hasta las obras publicadas en los años cuarenta. Nicolás Paso y Delgado (1841) elabora su propio manual siguiendo el camino trazado por Say, que desemboca en la consideración de la actividad empresarial como un factor productivo independiente del capital y del trabajo. Pero el camino continuaba y este autor no lo prosiguió, quizá por el objeto de su obra -un mero esbozo introductorio a la ciencia económica-, o tal vez por limitarse a exponer únicamente lo que comprendió, sin deseos de indagar en aspectos más complejos. Las consecuencias son la aparición de un empresario emprendedor que, sin saber por qué, inicia una actividad, y la incapacidad del autor para unir la producción con la distribución, si bien estaba en posesión de todas las herramientas para explicar esta relación.

\section{HETERODOXOS RICARDIANOS}

Hasta aquí los autores con filiación doctrinal o teórica a J. B. Say. A continuación nos adentramos en textos de escritores conocedores de la obra de Say, pero alejados de ella, al encontrar sus fundamentos en economistas que conocemos como ricardianos. Los dos autores seleccionados estuvieron presentes en la irrupción de esta escuela en Inglaterra, y ambos fueron también canales de difusión de la misma en España, aunque con diferente influencia entre sus compatriotas.

José Joaquín de Mora es un autor que, aun enmarcado casi exclusivamente en una problemática específica -el comercio exterior ${ }^{44}$-, es capaz de poner de manifiesto la imposibilidad de otorgar un lugar al empresario en el sistema teórico de la escuela de Ricardo ${ }^{45}$. José Joaquín de Mora se enfrenta a los problemas económicos con un trasfondo teórico concreto, en este caso muy lejano al de Say y muy cercano a Ricardo, en el que cualquier escenario posible para la aparición del empresario es ocupado por el capital ${ }^{46}$. En el trabajo de Mora (1834, p. 41) encontramos la división del trabajo como una cuestión vinculada al capital, o al capitalista organizador de la producción. Hay lugar -en la página 14- para un concepto de conocimiento que tiene como consecuencia la innovación, pero se trata de una variable exógena que permite mejorar la producción, más cercana al concepto de

\footnotetext{
${ }^{44}$ Pio Pita Pizarro es otro de los estandartes del librecambismo, y su influencia es extremadamente importante, ya que fue ministro de Hacienda en los años cuarenta: vid. al respecto Grice-Hutchinson (1982). En cuanto a la función empresarial, el término ganancia está presente junto al de salarios, pero es definida; incluso dentro de los comerciantes, tampoco hay referencias al empresario: Pita Pizarro (1833, p. 7). A priori podríamos pensar que estos defensores del comercio libre toman como referencia a J.-B. Say y con ello al empresario, sin embargo no hay referencias de ninguno de ellos.

${ }^{45}$ Véase al respecto O’Kean (1985).

${ }^{46}$ Martín Rodríguez (1989); Schwartz (1999).
} 
capital humano que a la innovación schumpeteriana. José Joaquín de Mora se limita a presentar una interesante clasificación de las innovaciones sin ninguna vinculación con el sistema teórico, ni con el productivo ni con el distributivo.

En Álvaro Flórez Estrada, cualquier aspecto vinculado a la actividad empresarial desaparece en los capítulos más inspirados en la obra de Say o en autores cercanos, como Destutt o Storch. En esos capítulos, Flórez (1835, p. 778) elude el empleo de términos esenciales para una teoría de la función empresarial, tales como «beneficio extraordinario» o «empresario» frente a «capitalista». Flórez evita en la medida de lo posible la inclusión del empresario porque se trata de un concepto innecesario, ya que la dirección es realizada por los operarios y el empleo de capital por los capitalistas. El progreso tecnológico sí adquiere un papel importante, tanto en forma de aumento de la eficiencia, como de innovaciones, pero su origen es la acumulación de capital, lo cual lo vincula al capitalista y lo aleja del empresario. En el modelo económico propuesto por Flórez Estrada no hace falta el empresario, por no ser condición necesaria del crecimiento, pero también por tener un sustituto denominado capitalista. La aparición de conceptos vinculados a la función empresarial sitúa a Flórez en la tradición analítica planteada por Turgot, muy lejos de las aportaciones de Say, aunque nuestro autor demuestre un importante conocimiento de la misma ${ }^{47}$.

\section{REFLEXIONES FINALES}

En España, la influencia de J. B. Say y de Richard Cantillon en los autores nacionales del siglo XIX supone un canal de entrada de la tradición francesa y la implantación del empresario en la teoría y en la política económica. El tempo de esta transmisión es diferente a las etapas originales de formación de ideas, si bien es cierto que las obras de Say se traducen sin retardo temporal con relación a las ediciones originales. El agitado comienzo de siglo marca la aparición de obras nacionales de espíritu reformista influidas por Adam Smith y por una tradición mercantilista en la que está inmerso Cantillon. Se trata de un magnífico sustento para recibir la obra de Say. En estos casos, si mayor es el distanciamiento de Smith, más protagonismo ocupa la actividad empresarial, ya sea por medio de la concepción de una demanda dinámica, del cálculo apriorístico o de la vinculación del conocimiento a la producción.

La restauración absolutista de 1814 señala la etapa de hegemonía teórica de la obra de Say, tan sólo interrumpida por esporádicas alternativas -traducciones y obras españolas-, más intensas en el Trienio liberal. A finales de los años veinte,

${ }^{47}$ Vid. Almenar (1980). 
el reinado de Say se convierte en la ortodoxia para los autores españoles que empiezan a publicar manuales orientados a una docencia emergente o textos de política económica. No nos atrevemos a jerarquizar por orden de importancia las causas de esta difusión, aunque sí a enumerarlas.

El propio debate sobre qué autor francés debe ser objeto de traducción y de difusión nos ofrece tres primeras explicaciones. En primer lugar, su país de procedencia; en segundo lugar, Say significa una clara diferenciación con relación a sus predecesores -tanto en la línea de los fisiócratas, como en la de Smith- porque supone un proyecto industrial, a diferencia de Garnier; en tercer lugar, su lenguaje es accesible a iniciados en la nueva ciencia, a diferencia de Canard. A esto añadimos que se trata de un proyecto docente muy completo, con el introductorio y básico Catéchisme, el Epítome como diccionario que define los conceptos, y el Traité como referencia teórica avanzada y completa.

A través de este gran canal de transmisión, la teoría económica del empresario de Say no se difundió en su plenitud, si bien el empresario estuvo presente en las obras de los autores españoles, y se diferenció su actividad de la simple aportación de capital. La absoluta desaparición de la naturaleza incierta de la remuneración empresarial -requisito para unir la producción y distribución en Say- pone de manifiesto la incompleta recepción de que fue objeto. En algunos casos, los autores españoles adoptaron su división penta-partita de los factores de la producción, pero naufragaron en la distribución y no fueron capaces de explicar el beneficio. Quizá por el mayor reflejo de unas empresas nacionales pequeñas y tendentes a la reducción de costes, la importancia de la búsqueda de eficiencia está presente en multitud de casos y la innovación ausente, algo que evidencia las características de un entorno adverso a novedades que modifiquen masivamente la estructura productiva.

Debemos advertir que esta situación no es excepcional en Europa; ya autores herederos de la obra de Say -Rau, Destutt, Storch- relegan, en el mejor de los casos, al empresario a un papel secundario. Sin embargo, en el panorama español sí podemos apuntar las causas de esta particular recepción. En primer lugar, encontramos una serie de restricciones iniciales, relacionados con la mera difusión de la obra de Say. En el caso de la teoría del empresario, el desinterés editorial por el Cours complet de 1828 supuso la inexistencia en castellano del texto más completo de J. B. Say sobre este tema. Por otro lado, la calidad de las traducciones también supuso un obstáculo, aunque se fue mitigando a lo largo de las distintas ediciones. En segundo lugar, estos autores sitúan aspectos puntuales de la función empresarial en la docencia de la nueva ciencia, pero alejados de los debates de política económica. El crecimiento económico no está vinculado a la actividad empresarial, ya que procede del desarrollo de las capacidades y de los capitales; las primeras se desarrollan con la formación, mientras que el conocimiento se extiende sin dificultad. Por tanto, este fondo no representa un problema, mientras que los capitales sí lo constituyen 
porque circulan y provocan insuficiencias que limitan la producción: de ahí las propuestas proteccionistas que eviten las salidas de capital y que fomenten las capacidades. Toda teoría de la función empresarial desemboca en estas políticas formativas y desaparece en el conjunto de las políticas de desarrollo.

En tercer lugar, aquellos que emplearon obras de autores cercanos a Say -como Joseph Droz, Karl H. Rau o Henry F. von Storch- realizaron una labor de filtros de la teoría del empresario, con desdichadas consecuencias: reducían la cuestión al problema del beneficio y suponían un paso atrás. Tan sólo el caso de Melchiorre Gioja supone un aire fresco en el rígido esquema clásico.

En cuarto lugar, los autores de influencia ricardiana, sobre todo Flórez Estrada, tendrán un gran protagonismo en la vida intelectual y, en nuestro objeto de estudio, supondrán un aislamiento del empresario de la actividad teórica. Si bien es cierto que varios autores españoles -Torrente o Jaumeandreu- reclamaron el reconocimiento de la actividad empresarial, la teoría del empresario de Jean-Baptiste Say tenía escasa presencia en unos textos propios con menor relevancia que el Curso de Flórez.

No podemos afirmar que la teoría del empresario se enriquezca con las aportaciones de los autores españoles. De hecho podríamos hablar de sorprendente retroceso, sobre todo ante la omnipresencia del concepto de hombre industrioso, que como hemos visto es anterior al de empresario. Si tomamos la teoría del empresario como indicador de la recepción de Say en España, vemos que ésta ha sido mucho menor de lo esperado a la vista de su éxito editorial. El miedo al vacío teórico y el deseo de diferenciar las obras nacionales del Traité, llevó, en unos casos, a adoptar influencias que desvirtuaron el pensamiento de Say y, en otros, a desviaciones nacionales con aplicaciones independientes de las teorías de Say.

\section{BIBLIOGRAFÍA}

Allix, E. (1910): «Jean Baptiste Say et les origines de l'industrialisme». Revue d'économie politique 24 (abril), pp. 303-313 y 341-63.

Almenar, S. (1980): «El pensamiento económico de Álvaro Flórez Estrada. Economía ricardiana y reformismo radical», en S. Almenar (ed.), Curso de economía política por D. Álvaro Flórez Estada. Madrid: Instituto de Estudios Fiscales, pp. XXIX-CXV.

- (1997): «Los primeros economistas clásicos y la industrialización», en VVAA, Industrialización en España: entusiasmos, desencantos y rechazos. Ensayos en homenaje al profesor Fabian Estapé. Madrid: Civitas, pp. 139-166.

Almenar, S., Argemí, L., y Lluch, E. (1999): «Els industrialismes a Espanya: 1840-1850», en A. Parejo y E. Sánchez (eds.), Economía andaluza e Historia industrial. Estudios en Homenaje a Jordi Nadal. Almería: Universidad de Almería, pp. 1.436-1.454.

Almenar, S. y Lluch, E. (2000): «Difusión e influencia de los economistas clásicos en España», en E. Fuentes Quintana (dir.), Economía y Economistas españoles. La economía clásica. Madrid: Galaxia Gutenberg, vol. 4, pp. 93-170. 
Baudeau, N. (1966) [1771]: Première introduction à la Philosophie Economique ou Analyse des Etat Policés, en E. Daire y H. Dussard (eds.), Collection des Principaux Economistes, vol 2, Physiocrates. Osnabrück: Otto Zeller, pp. 657-821.

Blanqui, A. (1945) [1837]: Histoire de l'économie politique, en C. Comte y H. Say (eds.), Cours complet d'économie politique pratique et mélange et correspondance d'économie politique. Bruselas: Société Typographique Belge.

Bolado, E. (2001): «Estudio de la difusión del pensamiento de J. A. Chaptal a través de sus traducciones al castellano: el caso del industrialismo prohibicionista catalán». Ponencia presentada al II Encuentro de la Asociación Ibérica de Historia del Pensamiento Económico, Oporto, 14 a 16 de diciembre de 2001.

Cabrillo, F. (1978): «Traducciones al español de libros de economía (1800-1880)». Moneda y Crédito 147, pp. 187-191.

Canga Argüelles, J. (1961) [1825]: Elementos de la Ciencia de la Hacienda con aplicación a España. Madrid: Instituto de Estudios Fiscales.

Carpeter, K. E. y Reduich, Fritz (1973): «Research Possibilities in the History of Political Economy Though: a Bibliography of Translations». History of Political Economy 5 (1), pp. 268-283.

Chaptal, J. A. (1819): De l'industrie francaise. París: Antoine-Augustin Renouard.

- (Traducción) (1834): Tratado de la industria francesa. Traducido y compendiado, é ilustrado con algunas notas por D. José Zorrilla de S. Martín. Madrid: Amarita.

Chassagne, S. (1983): «La formation des entrepreneurs à la période de l'industrialisation: l'example des entrepreneurs cotonniers», en VVAA, Entreprise et Entrepreneur XIXXXe. siécle. París: Presse Universitaire de Paris-Sorbonne, pp. 290-301.

Сомín, F. (2000): «Canga Argüelles: un planteamiento realista de la Hacienda liberal», en E. Fuentes Quintana (dir.), Economía y Economistas españoles. La economía clásica. Madrid: Galaxia Gutenberg, vol. 4, pp. 413-440.

Danvila y Villarrasa, B. (1779): Lecciones de Economía Civil. Madrid: Imprenta de Joaquín Ibarra.

De Capmany, A. (1817): Nuevo diccionario francés-español. Madrid: Imprenta de Sancha.

De las Heras Ibarra, D. (1813): Principios y Sistemas de Economía política, con relación a la situación de España, para la instrucción de los Diputados de provincia y toda clase de empleados de la Administración, aumento de la riqueza de los particulares, y arreglo de la economía eclesiástica. Madrid: Imprenta de Fuentenebro.

De Luna, G. (1819): Diferencia que hay entre la Estadística, Economía Política y Aritmética Política. Valladolid: Aparicio.

- (1819-20): Ensayo sobre la investigación de la naturaleza y causa de la riqueza de las naciones relativamente a España, o sea, la economía universal teórica aplicada a la nación española. Valladolid: Aparicio, Parte $1^{\text {a }}$ del tomo 1, 1819; Madrid: Espinosa, parte $2^{\text {a }}$ del tomo $1,1820$.

- (1820): Pensamientos de Economía-Política ó policía pública. Valladolid: Aparicio.

De Mora, J. J. (1834): Catecismo de Economía política. Londres y México: R. Ackermann.

- (1843): De la libertad del comercio. Sevilla: Tipografía de la Plaza del Silencio.

De Orense, C. (1813): Ideas económicas, políticas y morales. Cádiz: Imprenta del Estado Mayor General.

- (1820): Lecciones de Economía Política sobre población. Madrid: Imprenta de Vega y Cía. 
Efemérides de España (1805).

Espinosa de los Monteros, J. (1831): Tratado de Economía Política Aplicada a España. Madrid: Aguado.

EstaPÉ, F. (1971): «Algunos comentarios a la publicación del Ensayo sobre la naturaleza del comercio en general, de Cantillon», en Ensayos sobre Historia del pensamiento económico. Barcelona: Ariel, pp. 38-76.

Flórez Estrada, A. (1980) [1835]: Curso de Economía política. Madrid: Instituto de Estudios Fiscales.

Fontaine, P. (1989): «L'entrepreneur chez Turgot». París: Université Paris 1, Tesis doctoral.

FuRETIÈRE, A. (1690) Dictionnaire universel contenant généralement touts les mots français tant vieux que modernes, et les termes de toutes les sciences et des arts. Rotterdam: Ausgaben Den Haag.

Gassó, A. B. (1816): España con industria fuerte y rica. Barcelona: A. Brusi.

GioJA, M. (1815): Nuovo Prospetto delle sciense economiche ossia somma totale delle idee teoriche e pratiche in ogni ramo d'amministrazione privata e pubblica divise in antrettante classi, unite in sistema ragionato e generale. Milán: Pirota in Santa Radegonda.

Goglio, K. (2002): «L’Économie politique pratique et la gestion de l'entreprise chez JeanBaptiste Say», en J. P. Potier y A. Tiran (eds.), Jean-Baptiste Say: Nouveaux regards sur son oeuvre. París: Economica, pp. 535-554.

Grice-Hutchinson, M. (1995) [1982]: «La vicisitudes de un economista. Notas sobre el Catedrático don Manuel María Gutiérrez», en Ensayos sobre el pensamiento económico en España. Madrid: Alianza Editorial, pp. 153-180.

Gutiérrez, M. M. (1816): «Prólogo del Tratado de Economía política de J.B Say», en J. B. Say, Tratado de economía política ó simple exposición del modo con que se forman, distribuyen y consumen las riquezas. Madrid: Collado.

- (1819): Discurso inaugural y suscinta esposición de los principios de la economía política demostrados por Mr. Juan Bta. Say que en el acto de la instalación de las dos cátedras de economía y comercio dijo en Málaga el día 27 de marzo de 1818 en el salón del real tribunal del consulado real el profesor $M . M^{a}$ Gutiérrez. Málaga: Oficina de D. Luis de Carreras.

— (1828): «Economía política. Algodones». Correo Literario y Mercantil (5 de diciembre).

- (1831): «Prólogo a los Elementos de Economía política de James Mill», en J. Mill, Elementos de Economía política. Madrid: Imprenta de Miguel de Burgos, pp. 19-45.

- (1837): Impugnación a las cinco proposiciones de Preber sobre los grandes males que causa la ley de aranceles a la nación en general y a Cataluña en particular y a las mismas fabricas catalanas. Madrid: Imprenta de Don Marcelino Calero.

JaumeAndReu, E. (1814) Oración inaugural en la abertura de la Catedra de Economia Politica, establecida en la ciudad de Barcelona por la Real Junta de Comercio del Principado de Cataluña. Barcelona: Antonio Brusi.

- (1988) [1816]: Rudimentos de Economía Política. Barcelona: AltaFulla.

- (1836): Curso Elemental de Economía Política con aplicación a la legislación económica de España. Barcelona: De Gaspar.

LLuch, E. (1973): El pensament econòmic a Catalunya 1760-1840. Barcelona: Edicions 62.

- (1988): «Prólogo», en E. Jaumeandreu (1988), pp. 5-17. 
— (1992): «Juan López de Peñalver en los orígenes de la economía matemática», en Escritos de López de Peñalver. Madrid: Instituto de Estudios Fiscales.

López Castellano, F. (2000): «Lecciones de economía política sobre población de Casimiro Orense», en E. Fuentes Quintana (dir.), Economía y Economistas españoles. La economía clásica. Madrid: Galaxia Gutenberg, vol. 4, pp. 351-368.

LóPEZ de PeÑalver, J. (1992) [1812]: Reflexiones sobre la variación del precio del trigo, en E. Lluch (ed.), Escritos de Juan López de Peñalver. Madrid: Instituto de Estudios Fiscales.

Martín Rodríguez, M. (1989): «La institucionalización de la Economía política en la Universidad Española (1784-1857)», en E. Valle Santoro, Elementos de Economía política con aplicación particular a España. Madrid: Instituto de Estudios Fiscales, pp. IX-CCXXXVII.

Menudo, J. M. (2002): «La tradición francesa de la teoría económica del empresario y su influencia en los autores españoles decimonónicos». Sevilla: Universidad Pablo de Olavide. Tesis Doctoral.

Menudo, J. M. y O’kean, J. M. (2003): «The Entrepreneurial Function in A.R.J. Turgot». Ponencia presentada a Turgot (1727-1781). Notre contemporain? Economie, Administration et Législation au siècle des Lumières, Caen, 14 al 17 de mayo de 2003.

MERCURIO DE ESPAÑa (1801, 1804, 1819).

Mill, J. ( 1821) Elements of Political Economy. Londres: Baldwin, Cradock and Joy.

O’KeAn, J. M. (1985): «La función empresarial en la teoría económica clásica». Sevilla: Universidad de Sevilla. Tesis doctoral.

O’Kean, J. M. y Menudo, J. M. (2002): «La théorie de la fonction entrepreneuriale chez J.-B Say: La tradition Cantillon-Turgot-Say», en J.-P. Potier y A. Tiran (eds.), JeanBaptiste Say: Nouveaux regards sur son oeuvre. París: Economica, pp. 577-604.

Paso y Delgado, N. (1841): Elementos de Economía política y Estadística. Granada: Imprenta de Benavides.

Perdices, L. (2000): «La riqueza de las naciones y los economistas españoles», en E. Fuentes Quintana (dir.), Economía y Economistas españoles. La economía clásica. Madrid: Galaxia Gutenberg, vol. 4, pp. 279-303.

Pita Pizarro, P. (1833): Lecciones generales de comercio seguidas de una noción o rápida ojeada sobre la historia universal del mismo. Madrid: Imprenta Real.

Porlier Saenz de asteguieta, A. D. (1833): Las fuentes de la riqueza pública. Madrid: Imprenta de D.J. Espinosa.

Rau, K. H.(1839) [(1826]: Traité d'économie nationale. Bruselas: Hauman.

Real Academia Española (1791): Diccionario de la lengua castellana. Madrid: Imprenta de Joaquín Ibarra, $3^{a}$ edición.

Ricardo, D. (1821) [1817]: On the Principles of Political Economy and Taxation. Londres: John Murray.

SAVARY De Bourlons, J. (1741) [1723]: Dictionnaire universel du commerce, contenant tout ce que concerne le commerce qui se fait dans les quatre parties du monde, par terre, par mer, de proche en proche, et par des voyages de long cours, tant en gros qu'en détail. París: Estienne, 2 vols.

SaY, J.-B. (1803) Traité d'Economie Politique. París: Crapelet.

- (Traducción) (1804-1807): Tratado de Economía política o exposición sencilla de cómo se forman, se distribuyen y se consumen las riqueza. Madrid: Pedro María CaballeroGómez Fuentenebro. 
- (Traducción) (1816a): Tratado de economía política ó simple exposición del modo con que se forman, distribuyen y consumen las riquezas. Madrid: Imprenta de Collado.

- (1814): Epitome des principes fondamentaux de l'Economie politique. París: Déterville.

- (Traducción) (1816b): Epítome de los principios fundamentales de la Economía Política. Madrid: Imprenta de Collado.

- (1815a): Catéchisme d'économie politique ou Instruction familière qui montre de quelle façon les richesses sont produites, distribuées et consommées dans la société. París: Crapelet.

— (Traducción) (1816c): Cartilla de economía política, o instrucción familiar en forma de dialogo, que manifiesta el modo cómo se producen las riquezas en la sociedad. Madrid, Real Compañía, $1^{\text {a }}$ ed.

- (Traducción) (1816d): Principios de economía política, o instrucción familiar en forma de dialogo, que manifiesta el modo cómo se producen las riquezas en la sociedad. Madrid, Imprenta Real.

- (1815b): De l'Angleterre et des anglais. París: Bertrand.

- (Traducción) (1817a): De la Inglaterra y de los ingleses. Madrid: Imprenta de la Real Compañía y de Collado.

- (1817b): Petit volume contenant quelques aperçus des hommes et de la société. París: Déterville.

— (Traducción) (1839): Los hombres y la sociedad. Madrid: Imprenta de Boix.

- (1820a): Lettres à M. Malthus sur différents sujets d'économie politique, notamment sur les causes de la stagnation générale du commerce. París: Bossagne.

- (Traducción) (1820b): Cartas de Don Juan Bautista Say a Malthus sobre diferentes puntos de Economía Política y en especial sobre la estrangulación general del comercio. Madrid: Imprenta del Censor.

- (1845a) [1824a]: Commentaire sur le cours d'économie politique d'Henry Storch, en C. Comte et al. (eds.), Oeuvres diverses de J. B. Say. París: Guillaumin, pp. 288-341.

- (1824b): «Ensayo histórico sobre el origen, progreso y resultados probables de la soberanía de los ingleses en la India». Mercurio de España (diciembre).

- (1825): «Disertación sobre la balanza de los consumos y las producciones». Mercurio de España (marzo).

- (1826): Traité d'économie politique, ou simple exposition de la manière dont se forment, se distribuient et se consomment les richesses. París: Rapilly, $5^{\text {a }}$ edición.

- (Traducción) (1838): Tratado de economía política ó exposición de cómo se forman, se distribuyen y se consumen las riquezas. Madrid: Fuentenebro.

- (1828a): Cours completd'économie politique pratique; ouvrage destiné à mettre sous les yeux del hommes d'état, des propriétaires fonciers et des capitalistes, des savants, des agriculteurs, des manufacturiers, des négociants, et en général de touts les citoyens, l'économie des sociétés. París: Rapilly.

- (1845b) (1828b): Discours d'ouverture du cours d'économie industrielle, en C. Comte et al. (eds.), Oeuvres diverses de J.-B. Say. París: Guillaumin, pp. 148-161.

- (1841): Traité d'économie politique ou simple exposition de la manière dont se forment, se distribuent, et se consomment les richesses. París: Guillaumin, $6^{a}$ ed.

- (1845c): Cours Complet d'économie politique pratique, en C. Comte y H. Say (eds.), Cours Complet d'économie politique pratique et mélange et correspondance d'économie politique. Bruselas: Société Typographique Belge. 
Schumpeter, J. A. (1995) [1954]: Historia del análisis económico. Barcelona: Ariel.

Schwartz, P. (1999): "Una defensa del librecambio a mediados del siglo XIX», en P. Schwartz (ed.), De la libertad del comercio. Madrid: Ministerio de Economía y Hacienda, pp. VII-LXVII.

Sмiтh, A. (1904) [1776]: An Inquiry into the Nature and Causes of the Wealth of Nations. Londres: Methuen \& Co. Ltd., $5^{\text {a }}$ edición.

- (Traducción) (1794): Investigación de la naturaleza y causas de la riqueza de las naciones. Valladolid: Oficina de la Viuda e Hijos de Santander.

Sмiтн, R. S. (1968): «El pensamiento económico inglés en España (1776-1830)», en E. Fuentes Quintana (dir.), Economía y Economistas españoles. La economía clásica. Madrid: Galaxia Gutenberg, vol. 4, pp. 305-338.

STEIneR, P. (1996): «L'Économie politique comme science de la modernité», en P. Steiner (ed.), Cours d'économie politique et autres essais. París: Flammarion, pp. 9-46.

- (1998): «The structure of Say's economic writings». The European Journal of the History of Economic Thought 5 (2), pp. 227-49.

Torrente, M. (1835): Revista General de Economía Política. La Habana: Imprenta de Jordan. Velasco, R. (1990): Historia del pensamiento económico en Andalucía (1800-1850). Málaga: Editorial Librería Ágora.

Von Mangoldt, H. (1966) [1855]: Die Lehre vom Unternehmergewinn. Frankfurt: Sauer und Avermann.

WARD, B. (1982) [1779]: Proyecto económico. Madrid: Instituto de Estudios Fiscales. 